\title{
Utility of a Score for Predicting Glomerular Filtration Rate Overestimation in Patients with Cardiovascular and Renal Diseases and Their Risk Factors
}

\author{
Tomoyuki Ishigo ${ }^{1}$, Toshiyuki Yano ${ }^{2}$, Satoshi Katano ${ }^{3}$, Ryo Takada ${ }^{1}$, Tomohiro Aigami ${ }^{1}$, \\ Keita Nakano ${ }^{1}$, Fuki Kondo ${ }^{1}$, Hidemichi Kouzu ${ }^{2}$, Katsuhiko Ohori ${ }^{2,4}$, Hiromasa Nakata ${ }^{1}$, \\ Masatoshi Nonoyama ${ }^{1}$, Manabu Kitagawa ${ }^{1}$, Tomoko Kimyo ${ }^{1}$, \\ Masahide Fukudo ${ }^{1}$ and Tetsuji Miura ${ }^{2}$
}

\begin{abstract}
:
Objective We recently reported a novel score for the detection of glomerular filtration rate (GFR) overestimation using a creatinine-based equation. We examined the utility of this score in patients with cardiovascular/renal diseases and diabetes mellitus.

Methods We enrolled 1,425 patients ( $65 \pm 15$ years old; $37 \%$ women) who were admitted to our hospital for the management of cardiovascular and renal diseases and their risk factors. Overestimation of the GFR (OE) was defined as a creatinine-based GFR (eGFRcre) $\geq 120 \%$ of the cystatin C-based estimated GFR. The OE score was calculated as the sum of the scores for the body weight, hemoglobin concentration, and blood urea nitrogen $(\mathrm{BUN}) /$ serum creatinine (Scr), totaling 1 point if the body weight was $<63.0 \mathrm{~kg}$ in men or $<42.0 \mathrm{~kg}$ in women, 1 point if the hemoglobin concentration was $<12.4 \mathrm{~g} / \mathrm{dL}$ in men or $<11.0 \mathrm{~g} / \mathrm{dL}$ in women, and 1 point if the BUN/Scr was $>26.5$.

Results The proportion of patients with OE was $14.2 \%$. The score predicted OE with a sensitivity of $70.8 \%$ and a specificity of $99.6 \%$, and the sensitivity was increased in patients $\geq 75$ years old (88.3\%) and decreased in diabetics $(58.6 \%)$. When patients were divided into subgroups by the total score, the frequencies of $\mathrm{OE}$ were $8 \%(59 / 754), 14 \%$ (72/502), 38\% (58/151), and 72\% (13/18) in patients with scores of $0,1,2$, and 3 , respectively.

Conclusion The OE score is useful for detecting elderly cases of cardiovascular and renal diseases in which eGFRcre overestimates the GFR, although its utility is limited in diabetics.
\end{abstract}

Key words: creatinine, cystatin C, glomerular filtration rate, diabetes mellitus, chronic kidney disease, renal function

(Intern Med 61: 167-175, 2022)

(DOI: 10.2169/internalmedicine.7388-21)

\section{Introduction}

The accurate assessment of the renal function is crucial for making a diagnosis of and staging chronic kidney disease (CKD), selecting pharmacological agents, determining drug dosages and predicting the prognosis in patients with cardiovascular and renal diseases and risk factors for these diseases, such as hypertension, dyslipidemia, and diabetes mellitus (DM) (1). CKD is also frequently found in cancer patients, and chemotherapy and molecular-targeted therapy are associated with a risk of overt/subclinical kidney injury.

${ }^{1}$ Division of Hospital Pharmacy, Sapporo Medical University Hospital, Japan, ${ }^{2}$ Department of Cardiovascular, Renal and Metabolic Medicine, Sapporo Medical University School of Medicine, Japan, ${ }^{3}$ Division of Rehabilitation, Sapporo Medical University Hospital, Japan and ${ }^{4}$ Department of Cardiology, Hokkaido Cardiovascular Hospital, Japan

Received for publication February 22, 2021; Accepted for publication May 25, 2021

Correspondence to Dr. Toshiyuki Yano, tyano@sapmed.ac.jp 
(a)

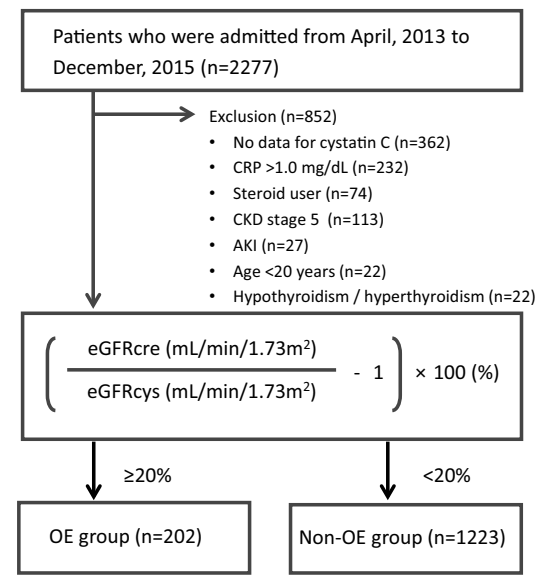

(b)

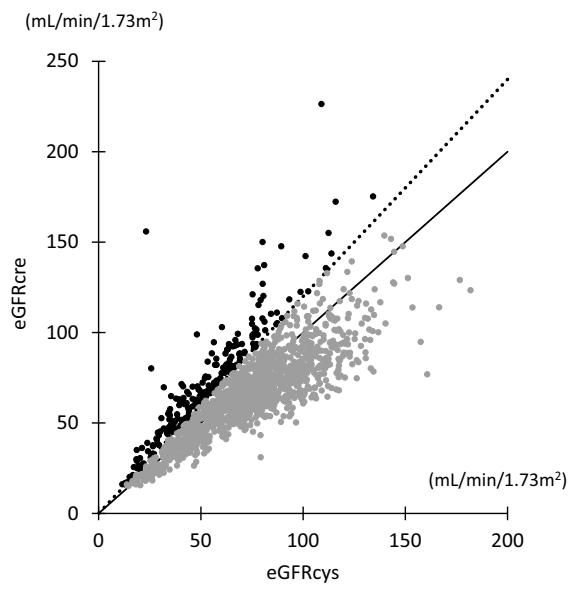

Figure 1. Inclusion of patients and the assessment of OE of the GFR. (a) Flow chart of the inclusion of study subjects. (b) Scatter plot showing discordance between eGFRcre and eGFRcys. OE of the eGFR by the eGFRcre was defined in cases with an eGFRcre $\geq 120 \%$ of the eGFRcys. Patients were classified into an OE group and a non-OE group. Black dots, OE group. Gray dots, non-OE group. CRP: C-reactive protein, CKD: chronic kidney disease, AKI: acute kidney injury, GFR: glomerular filtration rate, eGFRcre: creatinine-based estimated glomerular filtration rate, eGFRcys: cystatin C-based estimated glomerular filtration rate

If the dosages of such therapy are not adjusted to within the optimal ranges for the renal function, it can lead to extremely poor outcomes, including the development and progression of CKD (2). Thus, an accurate evaluation of the renal function is important in the complicated environment of a daily clinical setting.

The glomerular filtration rate (GFR), which is the rate of clearance of a substance from blood into urine, is the most acceptable indicator of the glomerular function $(3,4)$. Serum creatinine ( $\mathrm{Scr}$ ), a product of creatine phosphate from muscle, and serum cystatin $\mathrm{C}$, an endogenous protease inhibitor derived from all nucleated cells, are currently used for the GFR measurement, since both substances are considered good indicators of the GFR, as they are freely filtered at the glomerulus, and not reabsorbed by the renal tubule, although slight secretion of Scr by the renal tubule occurs $(3,4)$.

At present, the creatinine-based estimated glomerular filtration rate (eGFRcre) is the most widely used indicator for the estimation of the renal function in a daily clinical setting $(3,4)$. However, the eGFRcre in elderly people and lean patients is frequently higher than the cystatin C-based estimated glomerular filtration rate (eGFRcys), since the plasma appearance of creatinine is reduced in people with a reduced muscle mass (3-8). Since the measurement of cystatin $\mathrm{C}$ is more costly than that of Scr, it is not commonly included in routine examinations $(4,9)$. Therefore, a tool for identifying patients whose eGFR needs to be measured using cystatin $\mathrm{C}$ is likely to be useful in daily clinical practice.

A score for predicting GFR overestimation (OE) due to the use of Scr was developed in an earlier study, in which many participants with a body mass index (BMI) of $\geq 30 \mathrm{~kg}$ / $\mathrm{m}^{2}$ and participants of various races were included (10). We recently devised our own OE score to screen for cases with
OE by the eGFRcre among heart failure (HF) patients (4). In addition to the skeletal muscle mass measured by dualenergy X-ray absorptiometry, the body weight, hemoglobin level, and ratio of blood urea nitrogen (BUN) to Scr were shown to be independent predictors of OE (4). A score for the prediction of OE, composed of the body weight, hemoglobin level, and ratio of BUN to Scr, predicted OE with a good sensitivity (97.1\%) and a good specificity (98.1\%) among HF patients.

The present study investigated whether or not the $\mathrm{OE}$ score is applicable not only for HF patients but also for patients with cardiovascular and renal diseases and the associated risk factors.

\section{Materials and Methods}

This study was conducted in strict adherence with the principles of the Declaration of Helsinki and was approved by the Clinical Investigation Ethics Committee of Sapporo Medical University Hospital.

\section{Study subjects}

This study was a single-center, retrospective, observational study. Consecutive patients who were admitted to our department for the diagnosis and management of cardiovascular and renal diseases and their risk factors from April 1, 2013, to December 31, 2015, were retrospectively enrolled (Fig. 1a). Since active inflammation, thyroid dysfunction, and steroid therapy have been shown to modulate the serum cystatin $\mathrm{C}$ concentration in a GFR-independent manner $(4,11-14)$, patients with a C-reactive protein level of $>1$ $\mathrm{mg} / \mathrm{dL}$, those with hyperthyroidism/hypothyroidism, and those receiving corticosteroids were excluded. Patients $<20$ 
years old, those with an eGFRcre of $<15 \mathrm{~mL} / \mathrm{min} / 1.73 \mathrm{~m}^{2}$ or with acute kidney injury (AKI), and those with missing data were also excluded.

According to the Kidney Disease: Improving Global Outcomes (KDIGO) definition, AKI was defined in cases with any of the following: 1) increase in Scr by $\geq 0.3 \mathrm{mg} / \mathrm{dL}$ within 48 hours; 2) increase in Scr $\geq 1.5$ times baseline, which is known or presumed to have occurred within the prior 7 days; or 3) urine volume $<0.5 \mathrm{~mL} / \mathrm{kg} / \mathrm{h}$ for 6 hours (15).

\section{Laboratory data and echocardiography}

Patient's information and data for blood samples including data for Scr and cystatin $\mathrm{C}$ for calculation of eGFRcre and eGFRcys on the first day of admission were retrieved from the patients' medical records. eGFRcre and eGFRcys were calculated using equations developed for Japanese subjects as follows: eGFRcre $\left(\mathrm{mL} / \mathrm{min} / 1.73 \mathrm{~m}^{2}\right)=194 \times \mathrm{Scr}^{-1.094} \times$ $\operatorname{age}^{-0.287}\left(\times 0.739\right.$ for women) and eGFRcys $\left(\mathrm{mL} / \mathrm{min} / 1.73 \mathrm{~m}^{2}\right)$ $=104 \times \mathrm{CysC}^{-1.019} \times 0.996^{\text {age }}(\times 0.929$ for women $)-8(16)$. CKD was defined as an eGFRcre of $<60 \mathrm{~mL} / \mathrm{min} / 1.73 \mathrm{~m}^{2}$.

\section{Definition of eGFR OE}

The discordance between eGFRcre and eGFRcys was calculated as follows: (eGFRcre/eGFRcys-1) $\times 100(\%)$, as shown in Fig. 1. OE by the eGFRcre was defined in cases where the eGFRcre was $\geq 120 \%$ of the eGFRcys, as previously reported (4). Patients were classified into the OE or non-OE group.

\section{Definition of OE score and classification by total OE score}

The OE score was calculated as the summed scores for the body weight, hemoglobin concentration, and BUN/Scr, as previously reported (4): 1 point if the body weight was < $63.0 \mathrm{~kg}$ in men or $<42.0 \mathrm{~kg}$ in women, 1 point if the hemoglobin concentration was $<12.4 \mathrm{~g} / \mathrm{dL}$ in men or $<11.0 \mathrm{~g} / \mathrm{dL}$ in women, and 1 point if the BUN/Scr was $>26.5$.

\section{Statistical analyses}

Data are presented as the means \pm standard deviation or medians [interquartile range (IQR): $25-75$ th percentile] and expressed as the frequency and percentage. Welch's test was used to compare continuous variables in two groups. Differences in categorical variables between two groups were examined by the chi-squared test. The degree of $\mathrm{OE}$ for each group divided by the $\mathrm{OE}$ score was compared by the Kruskal-Wallis test, and the Steel-Dwass test was used for comparisons between each of the two groups. We calculated the sensitivity, specificity, positive predictive value (PPV), negative predictive value (NPV), and accuracy to evaluate the diagnostic ability of a score for OE in the subgroups of interest, i.e., age ( $<75$ and $\geq 75$ years old), and complications, such as CKD, DM, and hypertension. A p value $<0.05$ was considered statistically significant.

The software programs JMP ${ }^{\circledR}$ Pro 15 (SAS Institute, Cary,
USA) and EZR version 1.41 (Saitama Medical Center, Jichi Medical University, Saitama, Japan), which is a graphical user interface for R (The R Foundation for Statistical Computing, Vienna, Austria), were used for the statistical analyses in this study.

\section{Results}

Of the 2,277 enrolled patients, 852 were excluded based on the exclusion criteria, so the data for 1,425 patients were used for the analyses, as shown in Fig. 1a.

\section{Baseline clinical characteristics}

As shown in Table 1, the mean age of the patients was $64.8 \pm 14.9$ years old, and $37 \%$ of the patients were women. The mean body weight and BMI were $63.8 \pm 15.0 \mathrm{~kg}$ and $24.2 \pm 4.5 \mathrm{~kg} / \mathrm{m}^{2}$, respectively. Hypertension, dyslipidemia, DM, HF, ischemic heart disease (IHD), and valvular heart disease (VHD) were present in 42\%, 32\%, 26\%, 19\%, 40\%, and $4 \%$ of the patients, respectively. The mean values of eGFRcre and eGFRcys were $67.2 \pm 24.2 \mathrm{~mL} / \mathrm{min} / 1.73 \mathrm{~m}^{2}$ and $71.8 \pm 27.1 \mathrm{~mL} / \mathrm{min} / 1.73 \mathrm{~m}^{2}$, respectively, and $38 \%$ and $35 \%$ of the patients were diagnosed with CKD using eGFRcre and eGFRcys, respectively.

\section{Comparisons between the OE and non-OE groups}

The proportion of patients with OE was $14.2 \%$ (202/ 1,425 ) as shown in Fig. $1 \mathrm{~b}$ and Table 1. Patients in the OE group were significantly older than those in the non-OE group $(69.3 \pm 14.6$ vs. $63.7 \pm 14.8$ years old $)$ and included a larger proportion of women ( $48 \%$ vs. $36 \%$ ) than the non-OE group. In the OE group, the proportions of patients with $\mathrm{DM}, \mathrm{HF}$, and VHD were significantly higher than those in the non-OE group. The albumin concentration was lower in the OE group than in the non-OE group $(3.8 \pm 0.6$ vs. $4.1 \pm$ $0.4 \mathrm{~g} / \mathrm{dL})$, and the eGFRcre was higher $(73.5 \pm 33.0$ vs. $66.1 \pm$ $\left.22.2 \mathrm{~mL} / \mathrm{min} / 1.73 \mathrm{~m}^{2}\right)$ and the eGFRcys lower $(53.0 \pm 23.0$ vs. $74.9 \pm 26.5 \mathrm{~mL} / \mathrm{min} / 1.73 \mathrm{~m}^{2}$ ) in the $\mathrm{OE}$ group than in the non-OE group.

Validation of the OE score in patients with cardiovascular and renal diseases and associated risk factors

When patients were divided into 4 categories according to the total score, the frequencies of OE were $8 \%$ (59/754), $14 \%$ (72/502), 38\% (58/151), and 72\% (13/18) in patients with scores of $0,1,2$, and 3, respectively (Fig. 2). In analyses in which all patients were included (Table 2), a score of 1 for OE had an accuracy of $58.8 \%$, a sensitivity of $70.8 \%$, and a specificity of $56.8 \%$ for the prediction of OE, whereas a score of 3 had an accuracy of $86.4 \%$, a sensitivity of $6.4 \%$, and a specificity of $99.6 \%$ for the prediction (Table 3), indicating that the score predicted OE with a sensitivity of $70.8 \%$ and a specificity of $99.6 \%$ in the study subjects. The sensitivity of the score was increased in analyses in which patients $\geq 75$ years old were included (sensitivity, 
Table 1. Baseline Characteristics.

\begin{tabular}{|c|c|c|c|c|}
\hline & $\begin{array}{c}\text { All } \\
(\mathrm{n}=1,425)\end{array}$ & $\begin{array}{l}\text { OE group } \\
(\mathrm{n}=202)\end{array}$ & $\begin{array}{l}\text { Non-OE group } \\
(\mathrm{n}=1,223)\end{array}$ & $\mathrm{p}$ value \\
\hline Age, years & $64.8 \pm 14.9$ & $69.3 \pm 14.6$ & $63.7 \pm 14.8$ & $<0.001$ \\
\hline$\geq 65, \mathrm{n}(\%)$ & $797(55.9 \%)$ & $137(67.8 \%)$ & $660(54.0 \%)$ & $<0.001$ \\
\hline$\geq 75, \mathrm{n}(\%)$ & $358(25.1 \%)$ & $77(38.1 \%)$ & $281(23.0 \%)$ & $<0.001$ \\
\hline Female, n (\%) & $530(37.2 \%)$ & $96(47.5 \%)$ & $434(35.5 \%)$ & 0.001 \\
\hline Height, cm & $161.9 \pm 9.5$ & $157.9 \pm 9.5$ & $162.5 \pm 9.3$ & $<0.001$ \\
\hline Body weight, $\mathrm{kg}$ & $63.8 \pm 15.0$ & $58.9 \pm 15.9$ & $64.7 \pm 14.6$ & $<0.001$ \\
\hline BMI, $\mathrm{kg} / \mathrm{m}^{2}$ & $24.2 \pm 4.5$ & $23.4 \pm 5.5$ & $24.3 \pm 4.3$ & 0.005 \\
\hline \multicolumn{5}{|l|}{ Complications, n (\%) } \\
\hline Hypertension & $592(41.5 \%)$ & $77(38.1 \%)$ & $515(42.1 \%)$ & 0.317 \\
\hline Dyslipidemia & $453(31.8 \%)$ & $52(25.7 \%)$ & $401(32.8 \%)$ & 0.050 \\
\hline Diabetes mellitus & $374(26.2 \%)$ & $70(34.7 \%)$ & $304(24.9 \%)$ & 0.004 \\
\hline $\mathrm{HF}$ & $277(19.4 \%)$ & $60(29.7 \%)$ & $217(17.7 \%)$ & $<0.001$ \\
\hline IHD & $571(40.1 \%)$ & $72(35.6 \%)$ & $499(40.8 \%)$ & 0.188 \\
\hline VHD & $61(4.3 \%)$ & $17(8.4 \%)$ & $44(3.6 \%)$ & 0.004 \\
\hline \multicolumn{5}{|l|}{ Laboratory data } \\
\hline Albumin, g/dL & $4.1 \pm 0.5$ & $3.8 \pm 0.6$ & $4.1 \pm 0.4$ & $<0.001$ \\
\hline Hemoglobin, g/dL & $13.5 \pm 1.9$ & $12.6 \pm 2.2$ & $13.6 \pm 1.8$ & $<0.001$ \\
\hline $\mathrm{HbA} 1 \mathrm{c}, \%$ & $6.3 \pm 2.1$ & $6.4 \pm 1.6$ & $6.3 \pm 2.1$ & 0.493 \\
\hline Creatinine, $\mathrm{mg} / \mathrm{dL}$ & $0.9 \pm 0.4$ & $0.9 \pm 0.5$ & $0.9 \pm 0.4$ & 0.028 \\
\hline Cystatin C, mg/L & $1.1 \pm 0.5$ & $1.4 \pm 0.6$ & $1.1 \pm 0.4$ & $<0.001$ \\
\hline BUN, mg/dL & $18.4 \pm 8.6$ & $20.8 \pm 12.4$ & $18.0 \pm 7.8$ & $<0.001$ \\
\hline $\mathrm{BUN} / \mathrm{Scr}$ & $20.8 \pm 7.4$ & $25.7 \pm 12.2$ & $20.0 \pm 5.9$ & $<0.001$ \\
\hline eGFRcre, $\mathrm{mL} / \mathrm{min} / 1.73 \mathrm{~m}^{2}$ & $67.2 \pm 24.2$ & $73.5 \pm 33.0$ & $66.1 \pm 22.2$ & $<0.001$ \\
\hline eGFRcre $<60 \mathrm{~mL} / \mathrm{min} / 1.73 \mathrm{~m}^{2}, \mathrm{n}(\%)$ & $534(37.5 \%)$ & $68(33.7 \%)$ & $466(38.1 \%)$ & 0.240 \\
\hline eGFRcys, $\mathrm{mL} / \mathrm{min} / 1.73 \mathrm{~m}^{2}$ & $71.8 \pm 27.1$ & $53.0 \pm 23.0$ & $74.9 \pm 26.5$ & $<0.001$ \\
\hline eGFRcys $<60 \mathrm{~mL} / \mathrm{min} / 1.73 \mathrm{~m}^{2}, \mathrm{n}(\%)$ & $493(34.6 \%)$ & $127(62.9 \%)$ & $366(29.9 \%)$ & $<0.001$ \\
\hline
\end{tabular}

Data are presented as means \pm standard deviation or number (with percentage). $\mathrm{p}<0.05$ was considered statistically significant. BMI: body mass index, HbAlc: hemoglobin Alc, HF: heart failure, IHD: ischemic heart disease, VHD: valvular heart disease, BUN: blood urea nitrogen, BUN/Scr: ratio of blood urea nitrogen to serum creatinine, eGFRcre: creatinine-based estimated glomerular filtration rate, eGFRcys: cystatin C-based estimated glomerular filtration rate

$88.3 \%$; specificity, $98.9 \%$ ), whereas it was decreased in patients $<75$ years old (sensitivity, 60.0\%; specificity, 99.8\%). The specificity was similar among the subgroups of interest, whereas the sensitivity was higher in the subgroups with HF, IHD, and CKD and was lowest in patients with DM (Table 2). As shown in Fig. 3, the difference between eGFRcys and eGFRcre became larger as the total score increased.

\section{Characteristics of patients with OE among patients with a score of 0}

Among patients with a score of 0 , the group with $\mathrm{OE}$ included a higher percentage of women and had a higher BMI than did the group without OE, although there was no marked difference in age between the patients with and without OE (Table 3). The proportion of patients with $\mathrm{OE}$ who had DM was more than two-fold higher than the proportion without OE who had DM, but the proportions of patients with hypertension and dyslipidemia were similar in patients with $\mathrm{OE}$ and those without $\mathrm{OE}$ (Table 3). The plasma levels of albumin and eGFRcys were lower and those of hemoglobin A1c (HbA1c) and eGFRcre higher in patients with OE than in those without OE (Table 3).

\section{Discussion}

The main findings in the present study were as follows: 1) the score predicted the $\mathrm{OE}$ with a reasonable sensitivity $(70.8 \%)$ and a good specificity $(99.6 \%), 2)$ the sensitivity of the score for the prediction of $\mathrm{OE}$ was increased in analyses of patients $\geq 75$ years old, 3) the extent of discordance between eGFRcre and eGFRcys became larger as the total score increased, and 4) the sensitivity of the score for predicting $\mathrm{OE}$ was low in patients with DM. These findings suggest that cystatin $\mathrm{C}$ measurement is necessary for the accurate assessment of the eGFR in patients with a score of 3 and should be considered in those with a score of 1 or 2 .

There is no established tool for identifying patients whose eGFR needs to be measured using cystatin C. In a previous large-scale study, Peralta et al. developed a risk score for detecting patients with an occult-reduced eGFR, defined as having eGFRcys $<60$ and eGFRcre $>60 \mathrm{~mL} / \mathrm{min} / 1.73 \mathrm{~m}^{2}$, i. e. OE by the eGFRcre (10). Among 24,877 adults who had an eGFRcre of $>60 \mathrm{~mL} / \mathrm{min} / 1.73 \mathrm{~m}^{2}, 13.5 \%$ had an occultreduced eGFR. Variables that were selected by multivariable 
(a)

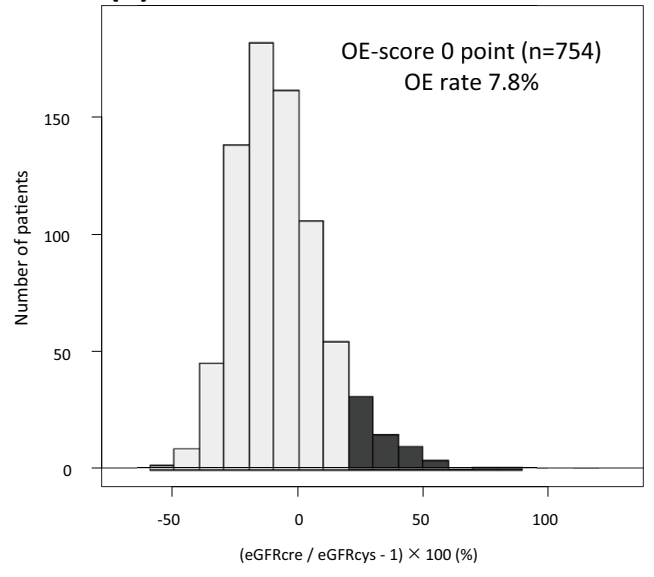

(c)

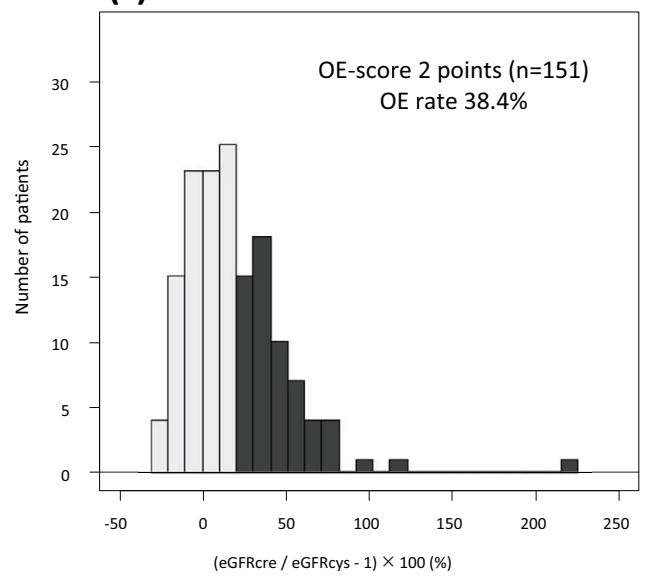

(b)

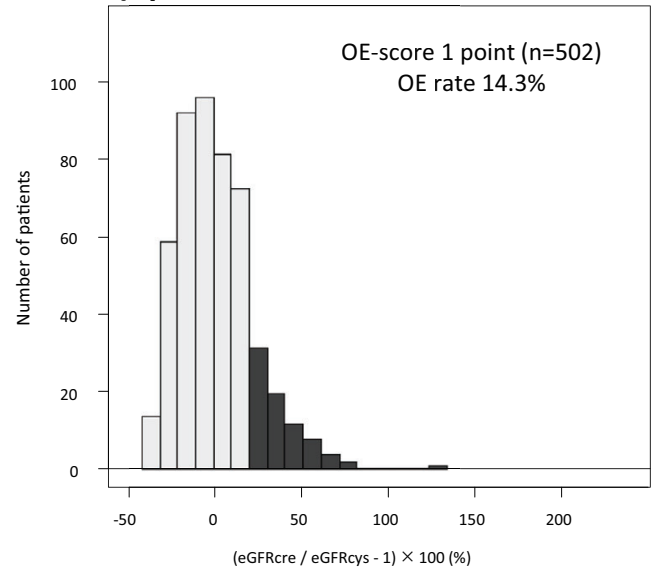

(d)

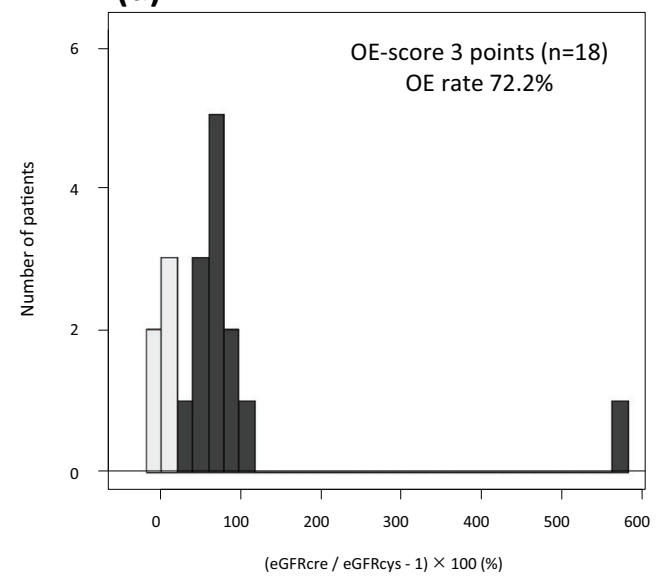

Figure 2. Frequencies of the GFR overestimation (OE) by the eGFRcre. Frequencies of GFR OE by the eGFRcre in patients with scores of 0 (a), 1 (B), 2 (c), and 3 (d). The total score is the sum of the scores for body weight, hemoglobin concentration, and BUN/Scr: 1 point if the body weight is $<63.0$ $\mathrm{kg}$ in men or $<42.0 \mathrm{~kg}$ in women, 1 point if the hemoglobin concentration is $<12.4 \mathrm{~g} / \mathrm{dL}$ in men or $<11.0$ $\mathrm{g} / \mathrm{dL}$ in women, and 1 point if the BUN/Scr is $>26.5$. OE of the eGFR by the eGFRcre was defined in cases with an eGFRcre $\geq 120 \%$ of the eGFRcys. GFR: glomerular filtration rate, OE: overestimation, eGFRcre: creatinine-based estimated glomerular filtration rate, BUN/Scr: ratio of blood urea nitrogen to creatinine, eGFRcys: cystatin C-based estimated glomerular filtration rate

logistic regression analyses for developing the risk score for predicting an occult-reduced eGFR were the age, race, BMI, eGFRcre, presence of DM and hypertension, history of cardiovascular disease, and smoking habit. Although the risk score reasonably predicted an occult-reduced eGFR, the results of the analyses in subjects with an eGFRcre of $>60$ $\mathrm{mL} / \mathrm{min} / 1.73 \mathrm{~m}^{2}$ could not be extrapolated to subjects in the present study, including CKD patients (38\%). Furthermore, the predictive ability of an occult-reduced eGFR varied according to the BMI and race, which is a reasonable finding, since previous studies have shown race/region-dependent variation in the skeletal muscle mass $(17,18)$. Taken together, these findings suggest that the risk score for predicting OE by the eGFRcre needs to be individualized according to race and BMI.

Several factors have been shown to modulate serum cystatin C levels. First, serum cystatin $\mathrm{C}$ levels have been shown to be positively correlated with inflammatory markers inde- pendently of the renal function (19). Second, a previous study revealed that the serum cystatin $\mathrm{C}$ level was elevated and eGFRcys was reduced under conditions of both subclinical hypothyroidism and subclinical hyperthyroidism (11). Third, the results of a study by Tsushita et al. in which the effects of doses of corticosteroids on the discordance between eGFRcys and eGFRcre were examined showed that eGFRcys/eGFRcre ratio decreases as the corticosteroid dose increases, leading to the conclusion that corticosteroids increase the serum cystatin $\mathrm{C}$ level, although corticosteroids have the potential to decrease the serum creatinine level through a reduction in the muscle mass (13). Although patients with these factors were excluded from the analyses in the present study to use eGFRcys as a reference standard of the GFR, other possible modulators of the serum cystatin $\mathrm{C}$ level have been reported. An older age, male gender, greater height/weight, and current cigarette smoking habit in addition to higher $\mathrm{C}$-reactive protein levels have 
Table 2. Diagnostic Ability of a Risk Prediction Score for EGFR Overestimation by EGFRcre.

\begin{tabular}{|c|c|c|c|c|c|c|c|c|c|c|c|}
\hline & Sensitivity & Specificity & PPV & NPV & Accuracy & $\mathrm{LR}+$ & LR- & $\mathrm{TP}$ & $\mathrm{TN}$ & FP & FN \\
\hline \multicolumn{12}{|c|}{ All $(n=1,425)$} \\
\hline 1 point & 0.708 & 0.568 & 0.213 & 0.922 & 0.588 & 1.640 & 0.514 & 143 & 695 & 528 & 59 \\
\hline 2 points & 0.351 & 0.920 & 0.420 & 0.896 & 0.839 & 4.386 & 0.705 & 71 & 1,125 & 98 & 131 \\
\hline 3 points & 0.064 & 0.996 & 0.722 & 0.866 & 0.864 & 15.742 & 0.939 & 13 & 1,218 & 5 & 189 \\
\hline \multicolumn{12}{|c|}{$<75$ years $(\mathrm{n}=1,067)$} \\
\hline 1 point & 0.600 & 0.623 & 0.174 & 0.922 & 0.620 & 1.592 & 0.642 & 75 & 587 & 355 & 50 \\
\hline 2 points & 0.288 & 0.954 & 0.456 & 0.910 & 0.876 & 6.309 & 0.746 & 36 & 899 & 43 & 89 \\
\hline 3 points & 0.040 & 0.998 & 0.714 & 0.887 & 0.886 & 18.840 & 0.962 & 5 & 940 & 2 & 120 \\
\hline \multicolumn{12}{|c|}{$\geq 75$ years $(\mathrm{n}=358)$} \\
\hline 1 point & 0.883 & 0.384 & 0.282 & 0.923 & 0.492 & 1.434 & 0.304 & 68 & 108 & 173 & 9 \\
\hline 2 points & 0.455 & 0.804 & 0.389 & 0.843 & 0.729 & 2.322 & 0.678 & 35 & 226 & 55 & 42 \\
\hline 3 points & 0.104 & 0.989 & 0.727 & 0.801 & 0.799 & 9.732 & 0.906 & 8 & 278 & 3 & 69 \\
\hline \multicolumn{12}{|c|}{ Hypertension $(\mathrm{n}=592)$} \\
\hline 1 point & 0.714 & 0.557 & 0.194 & 0.929 & 0.578 & 1.613 & 0.513 & 55 & 287 & 228 & 22 \\
\hline 2 points & 0.338 & 0.917 & 0.377 & 0.902 & 0.841 & 4.044 & 0.723 & 26 & 472 & 43 & 51 \\
\hline 3 points & 0.052 & 0.996 & 0.667 & 0.875 & 0.873 & 13.377 & 0.952 & 4 & 513 & 2 & 73 \\
\hline \multicolumn{12}{|c|}{ Dyslipidemia $(\mathrm{n}=453)$} \\
\hline 1 point & 0.615 & 0.613 & 0.171 & 0.925 & 0.614 & 1.592 & 0.627 & 32 & 246 & 155 & 20 \\
\hline 2 points & 0.231 & 0.938 & 0.324 & 0.904 & 0.857 & 3.702 & 0.820 & 12 & 376 & 25 & 40 \\
\hline 3 points & 0.019 & 0.998 & 0.500 & 0.887 & 0.885 & 7.712 & 0.983 & 1 & 400 & 1 & 51 \\
\hline \multicolumn{12}{|c|}{ Diabetes mellitus $(n=374)$} \\
\hline 1 point & 0.586 & 0.530 & 0.223 & 0.847 & 0.540 & 1.245 & 0.782 & 41 & 161 & 143 & 29 \\
\hline 2 points & 0.286 & 0.911 & 0.426 & 0.847 & 0.794 & 3.217 & 0.784 & 20 & 277 & 27 & 50 \\
\hline 3 points & 0.029 & 0.993 & 0.500 & 0.816 & 0.813 & 4.343 & 0.978 & 2 & 302 & 2 & 68 \\
\hline \multicolumn{12}{|l|}{$\mathrm{HF}(\mathrm{n}=277)$} \\
\hline 1 point & 0.800 & 0.447 & 0.286 & 0.890 & 0.522 & 1.447 & 0.447 & 48 & 97 & 120 & 12 \\
\hline 2 points & 0.483 & 0.857 & 0.483 & 0.857 & 0.775 & 3.383 & 0.603 & 29 & 186 & 31 & 31 \\
\hline 3 points & 0.133 & 0.986 & 0.727 & 0.805 & 0.801 & 9.644 & 0.879 & 8 & 214 & 3 & 52 \\
\hline \multicolumn{12}{|c|}{$\operatorname{IHD}(n=571)$} \\
\hline 1 point & 0.792 & 0.529 & 0.195 & 0.946 & 0.562 & 1.681 & 0.394 & 57 & 264 & 235 & 15 \\
\hline 2 points & 0.375 & 0.902 & 0.355 & 0.909 & 0.835 & 3.819 & 0.693 & 27 & 450 & 49 & 45 \\
\hline 3 points & 0.028 & 0.996 & 0.500 & 0.877 & 0.874 & 6.931 & 0.976 & 2 & 497 & 2 & 70 \\
\hline \multicolumn{12}{|c|}{ CKD $(n=534)$} \\
\hline 1 point & 0.794 & 0.500 & 0.188 & 0.943 & 0.537 & 1.588 & 0.412 & 54 & 233 & 233 & 14 \\
\hline 2 points & 0.471 & 0.869 & 0.344 & 0.918 & 0.818 & 3.595 & 0.609 & 32 & 405 & 61 & 36 \\
\hline 3 points & 0.088 & 0.989 & 0.545 & 0.881 & 0.875 & 8.224 & 0.922 & 6 & 461 & 5 & 62 \\
\hline
\end{tabular}

Body weight of $<63.0 \mathrm{~kg}$ in males or $<42.0 \mathrm{~kg}$ in females, hemoglobin concentration of $<12.4 \mathrm{~g} / \mathrm{dL}$ in males or $<11.0 \mathrm{~g} / \mathrm{dL}$ in females, and BUN/Scr of $>26.5$ count for 1 point. BUN/Scr: ratio of blood urea nitrogen to serum creatinine, PPV: positive predictive value, NPV: negative predictive value, LR+: positive likelihood ratio, LR-: negative likelihood ratio, TP: true positive, TN: true negative, FP: false positive, FN: false negative, HF: heart failure, IHD: ischemic heart disease, CKD: chronic kidney disease

been shown to be independently associated with serum cystatin C levels after adjusting for creatinine clearance (20). Indeed, an earlier study showed that the serum cystatin $\mathrm{C}$ level increases as the BMI increases (21). In addition, a positive impact of smoking on the serum cystatin $\mathrm{C}$ level was confirmed in a recent study showing that the serum cystatin $\mathrm{C}$ level was decreased three months after smoking cessation (22). Therefore, whether or not our score accurately predicts OE by the eGFRcre needs to be confirmed using GFR measurement with exogenous filtration markers, such as inulin.

One limitation of our OE score is its lower sensitivity for predicting the $\mathrm{OE}$ in patients with DM. This finding is explained by the results of analyses in which the clinical char- acteristics of patients who were classified into the OE group despite having a score of 0 were examined: among patients with a score of 0 , those who had $\mathrm{OE}$ had a higher BMI and cystatin $\mathrm{C}$ level as well as a higher prevalence of DM than did the patients without $\mathrm{OE}$. Thus, the serum cystatin $\mathrm{C}$ level might be elevated by an increase in the BMI, possibly through subclinical inflammation $(10,19-21)$ but not a decline in the renal function, leading to discordance between eGFRcre and eGFRcys. In addition, muscle wasting is frequently observed in patients with DM, regardless of increased fat mass, which is called sarcopenic obesity; this effect contributes to the co-existence of a reduced Scr level and increased body weight (23-25). Importantly, a reduction in hemoglobin levels and elevation in BUN levels, markers 
Table 3. Baseline Characteristics of Patients with OE Score of 0.

\begin{tabular}{|c|c|c|c|}
\hline & $\begin{array}{l}\text { OE group } \\
(\mathrm{n}=59)\end{array}$ & $\begin{array}{l}\text { Non-OE group } \\
\quad(\mathrm{n}=695)\end{array}$ & $\mathrm{p}$ value \\
\hline Age, years & $62.1 \pm 16.3$ & $60.1 \pm 14.5$ & 0.315 \\
\hline$\geq 65, \mathrm{n}(\%)$ & $34(57.6 \%)$ & $304(43.7 \%)$ & 0.042 \\
\hline$\geq 75, \mathrm{n}(\%)$ & $9(15.3 \%)$ & $108(15.5 \%)$ & 1.000 \\
\hline Female, n (\%) & $30(50.8 \%)$ & $245(35.3 \%)$ & 0.023 \\
\hline Height, cm & $160.2 \pm 9.3$ & $164.5 \pm 9.3$ & 0.001 \\
\hline Body weight, $\mathrm{kg}$ & $70.8 \pm 17.2$ & $69.5 \pm 15.1$ & 0.540 \\
\hline BMI, kg/m² & $27.5 \pm 6.0$ & $25.5 \pm 4.2$ & 0.001 \\
\hline \multicolumn{4}{|l|}{ Complications, $\mathrm{n}(\%)$} \\
\hline Hypertension & $22(37.3 \%)$ & $287(41.3 \%)$ & 0.584 \\
\hline Dyslipidemia & $20(33.9 \%)$ & $246(35.4 \%)$ & 0.888 \\
\hline Diabetes mellitus & $29(49.2 \%)$ & $161(23.2 \%)$ & $<0.001$ \\
\hline $\mathrm{HF}$ & $12(20.3 \%)$ & $97(14.0 \%)$ & 0.179 \\
\hline IHD & $15(25.4 \%)$ & $264(38.0 \%)$ & 0.067 \\
\hline VHD & $2(3.4 \%)$ & $21(3.0 \%)$ & 0.699 \\
\hline \multicolumn{4}{|l|}{ Laboratory data } \\
\hline Albumin, $\mathrm{g} / \mathrm{dL}$ & $4.0 \pm 0.4$ & $4.2 \pm 0.4$ & $<0.001$ \\
\hline Hemoglobin, g/dL & $14.2 \pm 1.7$ & $14.3 \pm 1.4$ & 0.803 \\
\hline $\mathrm{HbA} 1 \mathrm{c}, \%$ & $7.1 \pm 1.8$ & $6.3 \pm 2.5$ & 0.028 \\
\hline Creatinine, mg/dL & $0.8 \pm 0.2$ & $0.9 \pm 0.3$ & $<0.001$ \\
\hline Cystatin C, mg/L & $1.3 \pm 0.4$ & $1.0 \pm 0.3$ & $<0.001$ \\
\hline BUN, mg/dL & $15.1 \pm 5.2$ & $16.2 \pm 5.9$ & 0.172 \\
\hline $\mathrm{BUN} / \mathrm{Scr}$ & $20.4 \pm 3.9$ & $18.5 \pm 4.1$ & 0.001 \\
\hline eGFRcre, $\mathrm{mL} / \mathrm{min} / 1.73 \mathrm{~m}^{2}$ & $79.4 \pm 29.0$ & $68.0 \pm 20.3$ & $<0.001$ \\
\hline eGFRcre $<60 \mathrm{~mL} / \mathrm{min} / 1.73 \mathrm{~m}^{2}, \mathrm{n}(\%)$ & $14(23.7 \%)$ & $233(33.5 \%)$ & 0.148 \\
\hline eGFRcys, $\mathrm{mL} / \mathrm{min} / 1.73 \mathrm{~m}^{2}$ & $59.5 \pm 21.5$ & $78.4 \pm 24.1$ & $<0.001$ \\
\hline eGFRcys $<60$ mL/min $/ 1.73 \mathrm{~m}^{2}$, n (\%) & $32(54.2 \%)$ & $161(23.2 \%)$ & $<0.001$ \\
\hline \multicolumn{4}{|c|}{$\begin{array}{l}\text { Data are presented as means } \pm \text { standard deviation or number (with percentage). } p<0.05 \text { was } \\
\text { considered statistically significant. BMI: body mass index, HbAlc: hemoglobin Alc, HF: heart } \\
\text { failure, IHD: ischemic heart disease, VHD: valvular heart disease, BUN: blood urea nitrogen, } \\
\text { BUN/Scr: ratio of blood urea nitrogen to serum creatinine, eGFRcre: creatinine-based estimat- } \\
\text { ed glomerular filtration rate, eGFRcys: cystatin C-based estimated glomerular filtration rate }\end{array}$} \\
\hline
\end{tabular}

of malnutrition, are not typically found at this stage of DM if patients do not have advanced-stage diabetic nephropathy. Thus, a BMI-mediated but GFR-independent elevation in the serum cystatin $\mathrm{C}$ level, presence of sarcopenic obesity, and absence of malnutrition are likely the primary mechanisms underlying the lack of sensitivity of the score for predicting OE in patients with DM.

Intriguingly, the utility of the eGFR for assessing the renal function in diabetic patients is a matter of debate (25). The results of a cross-sectional study by Luis-Lima et al. showed that there was poor agreement between eGFRcre or eGFRcys and the GFR measured by the plasma clearance of iohexol ("measured GFR"), which was greater in patients with a measured GFR $<60 \mathrm{~mL} / \mathrm{min}$, leading to misclassification of CKD stages in approximately $30 \%$ of the study subjects (26). Given these findings, we believe that GFR measurement using exogenous filtration markers should be considered when planning dosing of drugs with a narrow therapeutic window and high toxicity in diabetic patients.

Several additional limitations associated with the present study warrant mention. First, since this study was a retrospective observational study with a limited number of study subjects, there might have been some selection bias in the study subjects. Second, the patients enrolled in the present study were those who had been admitted to our institute for the diagnosis and treatment of cardiovascular and renal diseases as well as their risk factors. The accuracy of a score for predicting OE of the GFR using eGFRcre needs to be confirmed in outpatients with a relatively stable condition. Finally, shrunken pore syndrome is a newly proposed clinical entity characterized by a high serum cystatin $\mathrm{C}$ concentration with a normal Scr concentration $(27,28)$, the presence of which may lead to discordance between eGFRcys and eGFRcre, since creatinine (113 Da) but not cystatin C (13.3 kDa) can pass through small-sized glomerular pores freely. However, there is currently no consensus concerning the presence or definition of shrunken pore syndrome.

In conclusion, a score for predicting OE of the GFR using eGFRcre in HF patients can be favorably applied to elderly patients with cardiovascular and renal diseases as well as their risk factors. However, its utility in diabetic patients is limited.

The authors state that they have no Conflict of Interest (COI). 
(a)

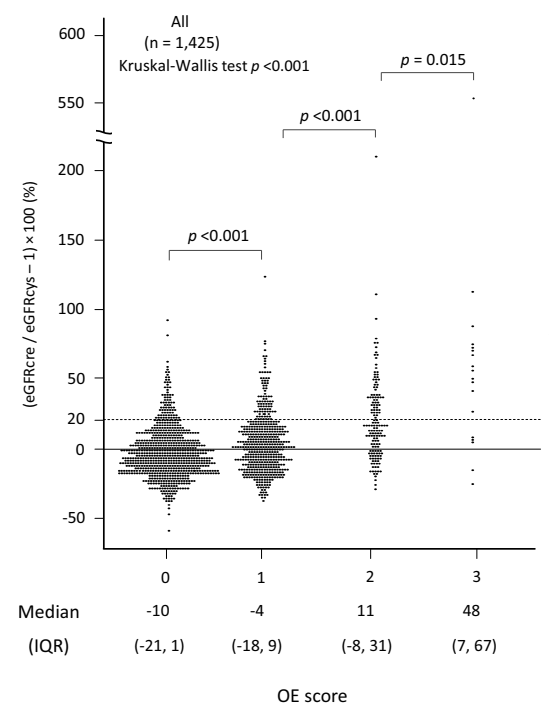

(b)

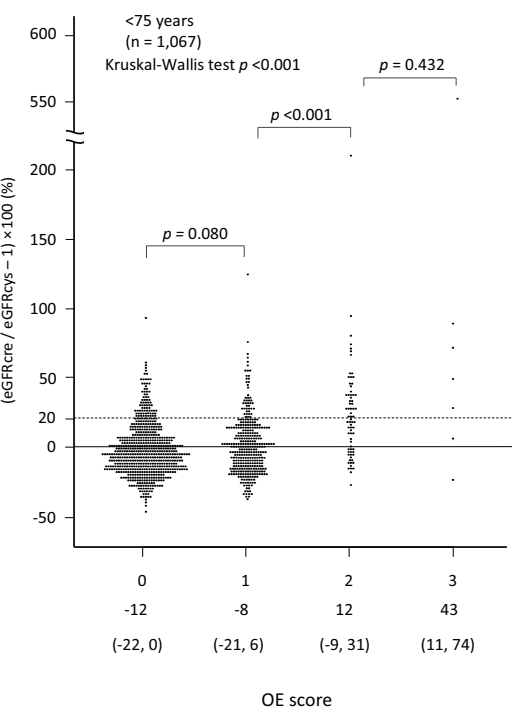

(c)

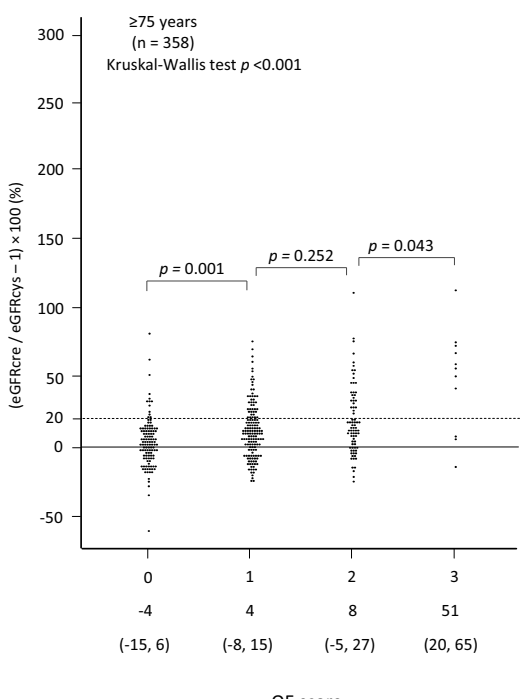

Figure 3. Distributions of discordance between eGFRcre and eGFRcys in groups with different scores. (a) Overall patients, (b) patients $<75$ years old, and (c) patients $\geq 75$ years old. The total score is the sum of the scores for body weight, hemoglobin concentration, and BUN/Scr: 1 point if the body weight is $<63.0 \mathrm{~kg}$ in men or $<42.0 \mathrm{~kg}$ in women, 1 point if the hemoglobin concentration is $<12.4 \mathrm{~g} / \mathrm{dL}$ in men or $<11.0 \mathrm{~g} / \mathrm{dL}$ in women, and 1 point if the BUN/Scr is $>26.5$. eGFRcre: creatinine-based estimated glomerular filtration rate, eGFRcys: cystatin C-based estimated glomerular filtration rate, BUN/Scr: ratio of blood urea nitrogen to creatinine

\section{Financial Support}

This study was supported by a grant (Ishigo T) from the Japanese Society of Nephrology and Pharmacotherapy.

Tomoyuki Ishigo and Toshiyuki Yano equally contributed to this work.

\section{References}

1. Rangaswami J, Bhalla V, Blair JEA, et al. Cardiorenal syndrome: classification, pathophysiology, diagnosis, and treatment strategies: a scientific statement from the American Heart Association. Circulation 139: e840-e878, 2019.

2. Torres da Costa E, Silva V, Costalonga EC, et al. Assessment of kidney function in patients with cancer. Adv Chronic Kidney Dis 25: 49-56, 2018.

3. Porrini E, Ruggenenti P, Luis-Lima S, et al. Estimated GFR: time for a critical appraisal. Nat Rev Nephrol 15: 177-190, 2019.

4. Ishigo T, Katano S, Yano T, et al. Overestimation of glomerular filtration rate by creatinine-based equation in heart failure patients is predicted by a novel scoring system. Geriatr Gerontol Int 20: 752-758, 2020

5. Abe K, Yano T, Katano S, et al. Utility of the sarcopenia index for assessment of muscle mass and nutritional status in patients with chronic heart failure: comparison with anthropometric parameters. Geriatr Gerontol Int 20: 388-389, 2020.

6. Raman M, Middleton RJ, Kalra PA, Green D. Estimating renal function in old people: an in-depth review. Int Urol Nephrol 49: 1979-1988, 2017.

7. Yamaguchi Y, Itabashi M, Yumura W, Takei T. Geriatric assessment of estimated glomerular filtration rate: a cross-sectional study. Clin Exp Nephrol 24: 216-224, 2020.

8. Legrand H, Werner K, Christensson A, Pihlsgård M, Elmståhl S.
Prevalence and determinants of differences in cystatin $\mathrm{C}$ and creatinine-based estimated glomerular filtration rate in communitydwelling older adults: a cross-sectional study. BMC Nephrol 18: 350, 2017.

9. Shardlow A, McIntyre NJ, Fraser SDS, et al. The clinical utility and cost impact of cystatin $\mathrm{C}$ measurement in the diagnosis and management of chronic kidney disease: a primary care cohort study. PLoS Med 14: e1002400, 2017.

10. Peralta CA, Muntner P, Scherzer R, Judd S, Cushman M, Shlipak MG. A risk score to guide cystatin $\mathrm{C}$ testing to detect occultreduced estimated glomerular filtration rate. Am J Nephrol 42: 141-147, 2015.

11. Shlipak MG, Katz R, Cushman M, et al. Cystatin-C and inflammatory markers in the ambulatory elderly. Am J Med 118: 1416, 2005.

12. Ye $\mathrm{Y}$, Gai $\mathrm{X}$, Xie H, Jiao L, Zhang S. Impact of thyroid function on serum cystatin $\mathrm{C}$ and estimated glomerular filtration rate: a cross-sectional study. Endocr Pract 19: 397-403, 2013.

13. Zhai JL, Ge N, Zhen Y, Zhao Q, Liu C. Corticosteroids significantly increase serum cystatin $\mathrm{C}$ concentration without affecting renal function in symptomatic heart failure. Clin Lab 62: 203-207, 2016.

14. Tsushita H, Tanaka R, Suzuki Y, Sato Y, Itoh H. Effects of dose and type of corticosteroids on the divergence between estimated glomerular filtration rates derived from cystatin $\mathrm{C}$ and creatinine. J Clin Pharm Ther 45: 1390-1397, 2020.

15. KDIGO AKI Work Group. KDIGO clinical practice guideline for acute kidney injury. Kidney Int Suppl 2: 1-138, 2012.

16. Horio M, Imai E, Yasuda Y, et al.; Collaborators developing the Japanese equation for estimated GFR. GFR estimation using standardized serum cystatin C in Japan. Am J Kidney Dis 61: 197203, 2013.

17. Gerace L, Aliprantis A, Russell M, et al. Skeletal differences between black and white men and their relevance to body composition estimates. Am J Hum Biol 6: 255-262, 1994. 
18. Ortiz O, Russell M, Daley TL, et al. Differences in skeletal muscle and bone mineral mass between black and white females and their relevance to estimates of body composition. Am J Clin Nutr 55: 8-13, 1992.

19. Keller C, Katz R, Cushman M, Fried LF, Shlipak M. Association of kidney function with inflammatory and procoagulant markers in a diverse cohort: a cross-sectional analysis from the Multi-Ethnic Study of Atherosclerosis (MESA). BMC Nephrol 9: 9, 2008.

20. Knight EL, Verhave JC, Spiegelman D, et al. Factors influencing serum cystatin $\mathrm{C}$ levels other than renal function and the impact on renal function measurement. Kidney Int 65: 1416-1421, 2004.

21. Muntner P, Winston J, Uribarri J, Mann D, Fox CS. Overweight and obesity and elevated serum cystatin $\mathrm{C}$ levels in US adults. Am J Med 121: 341-348, 2008.

22. Funamoto M, Shimizu K, Sunagawa Y, et al. Serum cystatin C, a sensitive marker of renal function and cardiovascular disease, decreases after smoking cessation. Circ Rep 1: 623-627, 2019.

23. Yano T, Katano S, Kouzu H, et al. Distinct determinants of muscle wasting in nonobese heart failure patients with and without type 2 diabetes mellitus. J Diabetes 13: 7-18, 2021.

24. Wang M, Tan Y, Shi Y, Wang X, Liao Z, Wei P. Diabetes and sar- copenic obesity: pathogenesis, diagnosis, and treatments. Front Endocrinol (Lausanne) 11: 568, 2020.

25. Wood N, Straw S, Scalabrin M, Roberts LD, Witte KK, Bowen TS. Skeletal muscle atrophy in heart failure with diabetes: from molecular mechanisms to clinical evidence. ESC Heart Fail 8: 3$15,2021$.

26. Luis-Lima S, Higueras Linares T, Henríquez-Gómez L, et al. The error of estimated GFR in type 2 diabetes mellitus. J Clin Med 8: $1543,2019$.

27. Grubb A, Lindström V, Jonsson M, et al. Reduction in glomerular pore size is not restricted to pregnant women. Evidence for a new syndrome: 'Shrunken pore syndrome'. Scand J Clin Lab Invest 76: 74-81, 2016.

28. Almén MS, Björk J, Nyman U, et al. Shrunken pore syndrome is associated with increased levels of atherosclerosis-promoting proteins. Kidney Int Rep 4: 67-79, 2018.

The Internal Medicine is an Open Access journal distributed under the Creative Commons Attribution-NonCommercial-NoDerivatives 4.0 International License. To view the details of this license, please visit (https://creativecommons.org/licenses/ by-nc-nd/4.0/).

(C) 2022 The Japanese Society of Internal Medicine Intern Med 61: 167-175, 2022 